\title{
Construction of Mathematical Model of DC Servo Motor Mechanism with PID controller for Electric Wheel Chair Arrangement
}

\section{Hadish Habte Tesfamikael}

Graduate Assistant, Mainefhi College of Engineering, Asmara, Ministry of Education, Eritrea. hadushabte94@gmail.com

\section{Adam Fray}

Junior telecommunication engineer, Ministry of Telecommunication, Asmara, Eritrea.

\section{Israel Mengsteab}

Junior power engineer, Ministry of Defense, Asmara, Eritrea.

\section{Adonay Semere \\ Junior telecommunication engineer, Ministry of Telecommunication, Asmara, Eritrea.}

\section{Zebib Amanuel}

Electrical Installation supervisor, Ministry of Defense, Asmara, Eritrea

\begin{abstract}
Low-level and medium-level leg injury patients can be operated wheelchair independently in the clinical region. The construction of an electric wheelchair is one of the solutions to operate electric wheelchair by the patients themselves. The motor is an essential part of an electrical wheelchair for driving from one place to another place. The response of the system is very important for the optimization of the system. The existing methods fail in gradual sensitivity during motion and lack of response time to the user. This article is consist of a design for optimizing the existing DC motor transfer function for the smart wheelchair. The perfect angular tuning of the derivative controller provides a better executing time for our proposed model. The smoother responses from the smart wheelchair are obtaining by the dynamic response of closed-loop control. The design of DC motors is to drive smart wheelchair as per the needs. Besides, the construction of a mathematical model for proposing a system involves the DC motor drive to the smart wheelchair arrangement. The proposed model gives independent
\end{abstract}


Journal of Electronics and Informatics (2021)

Vol.03/ No.01

Pages: 49-60

https://www.irojournals.com/iroei/

DOI: https://doi.org/10.36548/jei.2021.1.005

mobility of smart wheelchair with less response time and better sensitivity. Here, the mathematical model provides the details of immediate response to the user and less execution time of the complex system process. Finally, the authors discussed future improvements to the current DC motor design in the proposed system.

\section{Keywords: DC motor, PID controller}

\section{INTRODUCTION}

In ancient times, the joystick-based wheelchair is more popular and human controllable everywhere. Recently, technology has grown up and life becomes sophisticated with more comfort of less effort [1]. For more safety and comfort, the wheelchair is interfacing with many controlling devices for their mobility with less effort. Patients with severe conditions will not be able to use an independent electrical wheelchair device [2]. Assistive devices are essential in every hospital for patients with leg injuries and the elderly. In the past, conventional wheelchairs were controlled by a simple joystick [3].The smart wheelchair is one of those assistive devices. The manual wheelchair requires another human to operate it. The electric wheelchair (EWC) is more effective and it is used to improve people's quality of life [4]. The EWC is consumes electric power and replaces human resources. It also assembles the motors to drive from one place to another place without any human intervention. Furthermore, a heavy load cannot be transported over long distances in the hospital zone. The man who was carried will easily become fatigued due to the long distance with the massive weight [5]. The EWC gives those people more independence in their way of life. Patients who suffered from spinal cord injuries can operate easily for smoother mobility [6].

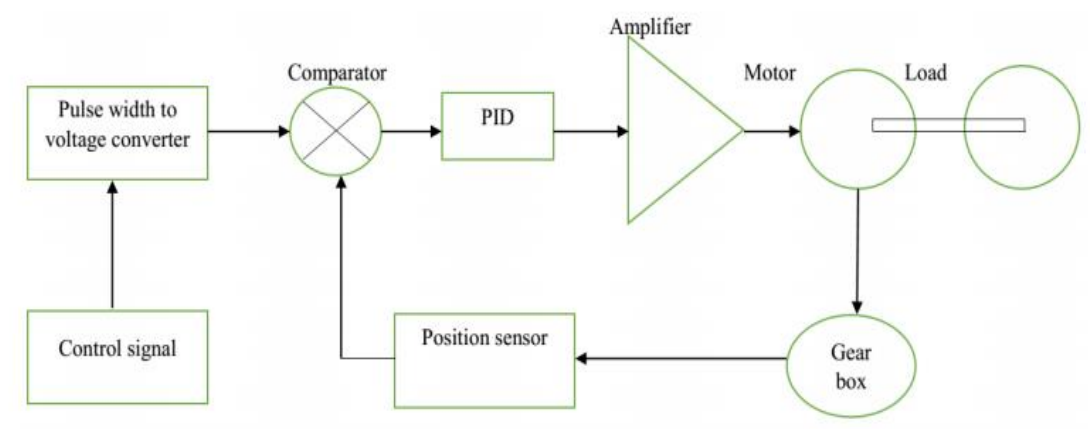

Figure 1 Block diagram representation of Servomotor Mechanism 
Journal of Electronics and Informatics (2021)

Vol.03/ No.01

Pages: 49-60

https://www.irojournals.com/iroei/

DOI: https://doi.org/10.36548/jei.2021.1.005

Many smart wheelchairs are incorporating many technologies such as voice recognition and vision recognition-based. But it should be operated with a motorized driver to drive from one location to another. The DC servo motors are moderately simple setup and working principle aids to modify according to our desires [7]. The setup comprises of small dc motor and encoder position control mechanism with the potentiometer. The variation of the potentiometer, the smooth variation in the dc motor rotation. The encoder position sensor is derived for feedback control of one radian per rotation [8].

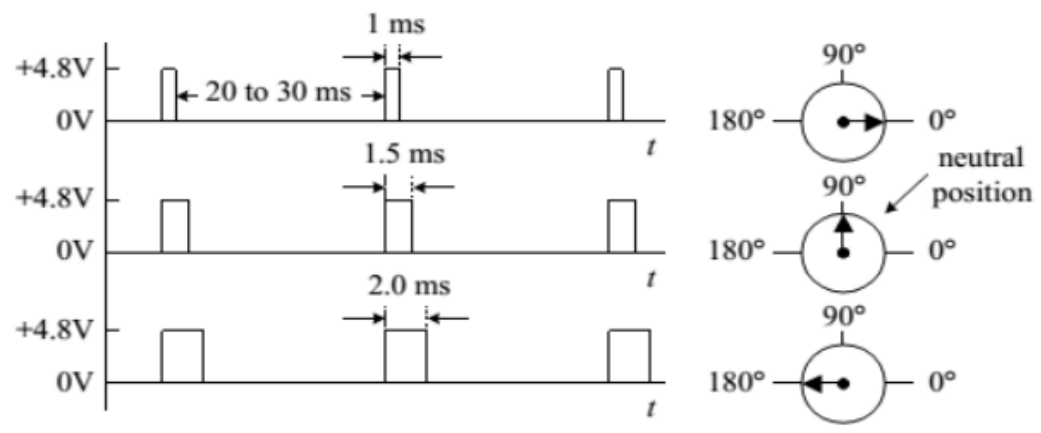

Figure 2 Servo motor shaft positioning control

The shaft of the motor can be rotated in the reverse way to produce electrical pulses for controlling it. The motor's speed is proportional to the difference between the actual and desired positions [9]. If the difference is small, the rotation of the rotor is very slow and vice versa. Therefore, the controlling of the difference between the position provides a good smoother control mechanism. The produced pulse varies to control the shaft position and its rotation can be altered [10].

\section{ORGANIZATION OF THE RESEARCH}

The following is the structure of the research article. Section 3 describes existing methods for controlling the smart wheelchair's DC motor. The proposed derivation of the mathematical model for DC motor tuning with a PID controller is presented in Section 4. Section 5 explores the specific details of the obtained results and graphs. Finally, Section 6 concludes the research work. 
Journal of Electronics and Informatics (2021)

Vol.03/ No.01

Pages: 49-60

https://www.irojournals.com/iroei/

DOI: https://doi.org/10.36548/jei.2021.1.005

\section{PRELIMINARIES}

The hand gesture control system-based wheelchair is provides comfortability for leg injuries human community. With the help of accelerometer control, the EWC is operating through hand positons by the computer-interpreted signal. These data were standardized and clarified by a mathematical model [11]. The movement of the head and chin is another type of steering control for the EWC [12]. Many researchers have investigated that wheelchairs are operated through control from the human tongue. The assistive device is comprised of 18 sensors with a 10-layer printed circuit board (PCB) and a microcontroller unit with a radio chip. The ferromagnetic-based tongue piercing touches the sensor and gives a signal due to an inductive function [13]. Artificial Intelligence (AI) technology is used in the motion of EWC accurate and more sensitive manner. The face expression is determined to drive the motor in EWC which is the most popular technique through knowledge-based control unit [14]. The voice command is used as input EWC. For the high-security reason, the system voice recognition algorithms are used for driving forward, right and left side, backward. The coding for the signal is sent to the microcontroller which monitors the EWC [15]. The smart wheelchair is moved by wireless hand gesture control system. The hand gesture directs the smart wheelchair by showing front side and back side. Here, the accelerometer is used to collect the data and work accordingly [16]. Generally, this data is calibrating to drive the wheelchair securely. This device is connected with android mobile devices called IoT. The devices can be operated from anywhere. Making success in this product, safety and security is a big challenge task in the internet world [17]. The robot operating wheelchair is very popular in the developed countries. The wheelchair is controlled by a robot through an intranet working in any place [18]. The smartphone is connected with EWC which is used to capture and record the patient's facial expression. This can read, rotate, and translate as voice recording [19]. Bluetooth wireless technology can be applied in the application of wheelchairs. This wheelchair is getting the direction from tilting of smartphone [20].

The EWC is controlled by a DC servo motor for direction determination by incorporating it with a microcontroller [21]. The movement of the wheelchair is based on the voice command of the patients. But it is very sensitive to noise interruption. This recognition of commands to the wheelchair is controlled by a smartphone. Security measures have to be taken for the dynamic response of the system [22]. The DC motor fuzzy control system was proposed by Lin et al., 
Journal of Electronics and Informatics (2021)

Vol.03/ No.01

Pages: 49-60

https://www.irojournals.com/iroei/

DOI: https://doi.org/10.36548/jei.2021.1.005

have incorporated a PID controller with the currently proposed system that produced a good response to the procedure [23]. Misra et al., compared the performance between the PID and FLC servomotor control for the various parameter. And also proposed a FLC-based PID controller for a motor drive with a different variation of the load [24]. Kwon et al., proposed the BLDC motor control for various loads during the operation with the dynamic condition. The construction of an adaptive fuzzy system is incorporated with controller parameters for better tuning procedure [25]. M.H Zadeh et al., discussed time-varying condition along with control of DC motor. This procedure can provide a good dynamic response to the system [26].

\section{METHODOLOGIES}

The construction of the DC servo motor mechanism is significant to EWC for dynamic response. Besides, the system has to model with load, sensor, and controlling unit. The voltagebased amplifier is considered for the DC servomotor system. The sensor output will be assigned as digital data for different angles as shown in figure 3.
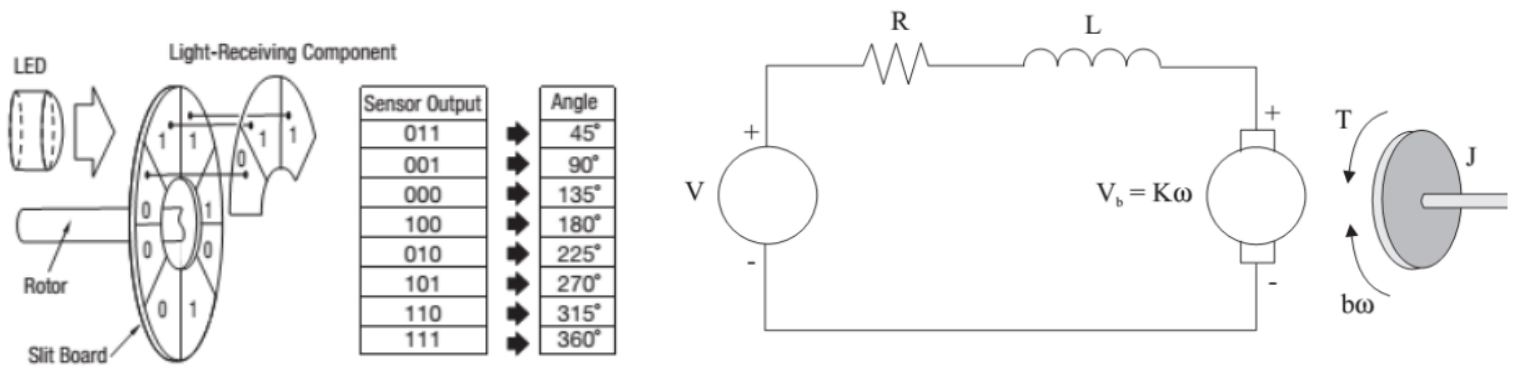

Figure 3 (a) Digital data for absolute encoder (b) Closed loop circuit diagram for servomotor

To find the transfer function of the proposed system, consider

$$
U=K_{v} V
$$

By KVL,

$$
\begin{gathered}
V(t)=R i(t)+L \cdot \frac{d i(t)}{d t}+v_{b}(t) \\
v=R I+s L I+k w
\end{gathered}
$$


Journal of Electronics and Informatics (2021)

Vol.03/ No.01

Pages: 49-60

https://www.irojournals.com/iroei/

DOI: https://doi.org/10.36548/jei.2021.1.005

\section{STEP 1:}

The angular rotation can be determined by shaft limited by a pulse width modulated (PWM) wave. Based on the internal gear system, the shaft provides substantial torque for the speed.

$$
J_{\alpha}+T_{f}=T_{g}
$$

Where,

$$
\begin{aligned}
\alpha=\frac{d \omega}{d t} & \omega=\int \alpha d t & \omega=\frac{1}{s} \alpha \\
\omega=\frac{d \theta}{d t} ; & \theta=\int \omega d t & \theta=\frac{1}{s} \omega
\end{aligned}
$$

When combined, the equation will be $\frac{\theta}{V}=\frac{k_{a} v_{t}}{J_{s} s 2}$

\section{STEP 2:}

There is an impressive full-swing procedure in switching mechanisms with moderate conditions. The DC servomotor comprises three supply colored wires such as black, red, and white for power supply, ground and shaft position controlling respectively.

System modelling,

$$
\begin{gathered}
U=1 / k t \\
M(s)=\frac{\omega}{U}=k t\left(s^{2} j \omega L+s J r \omega+k_{e} k t \omega\right. \\
U=K_{v} V \\
M(s)=\frac{1}{K e(s T m+1)(s T e+1)} \\
\frac{\theta}{V}=\frac{K v}{K e S(s T m+1)(s T e+1)}
\end{gathered}
$$

\section{STEP 3:}

When the motor starts, it is connected to a series of gears in its internal arrangement. The rotor's rotation is controlled by potentiometer resistance. Generating encoder transfer function,

$$
k_{f}=\frac{2^{n}}{2 \pi}=10,435 \text { counts per radians }
$$

Consider, $E=R-C$

ISSN: 2582-3825 (online) 
Journal of Electronics and Informatics (2021)

Vol.03/ No.01

Pages: 49-60

https://www.irojournals.com/iroei/

DOI: https://doi.org/10.36548/jei.2021.1.005

\section{STEP 4:}

The control circuit can be altered by shaft position derivation with the modified angular condition of the PWM procedure. This amount of torque will be the varied for the same servomotor due to the internal coil setup arrangement. Here, PID controller is applied through various forms as $\mathrm{P}, \mathrm{I}$, and $\mathrm{D}$.

$$
\begin{gathered}
X_{p}=P . E \\
X_{d}=s D \cdot E \\
X_{i}=\frac{I}{S} \cdot E
\end{gathered}
$$

The summation of all various controller,

$$
X=X_{p}+X_{d}+X_{i}
$$



Figure 4 DC servomotor solution of transfer function equation

$$
F(s)=P+s D+\frac{I}{S}
$$

\section{STEP 5:}

Proposing Transfer function of DC Motor,

$$
\begin{gathered}
\frac{v_{a}(s)}{\theta(s)}=\frac{K}{\left(s^{2} J+s D\right)(R a+L a s)+k 2 s} \\
=\frac{1}{s}\left(\frac{K}{(J s+D)(R a+L a)+k 2}\right)
\end{gathered}
$$

This is designed with motor torque value, and motor specifications. 
Journal of Electronics and Informatics (2021)

Vol.03/ No.01

Pages: 49-60

https://www.irojournals.com/iroei/

DOI: https://doi.org/10.36548/jei.2021.1.005

\section{RESULTS AND DISCUSSION}

After constructing the DC servomotor subsystem in MATLAB Simulink, the angular speed with respect to time will be calculated. The angular speed graph shows in the figure and its position vary based on the shaft encoder output [27]. Figure 5 shows the simulation construction of the DC servomotor. The speed vs time graph is shown in figure 6.

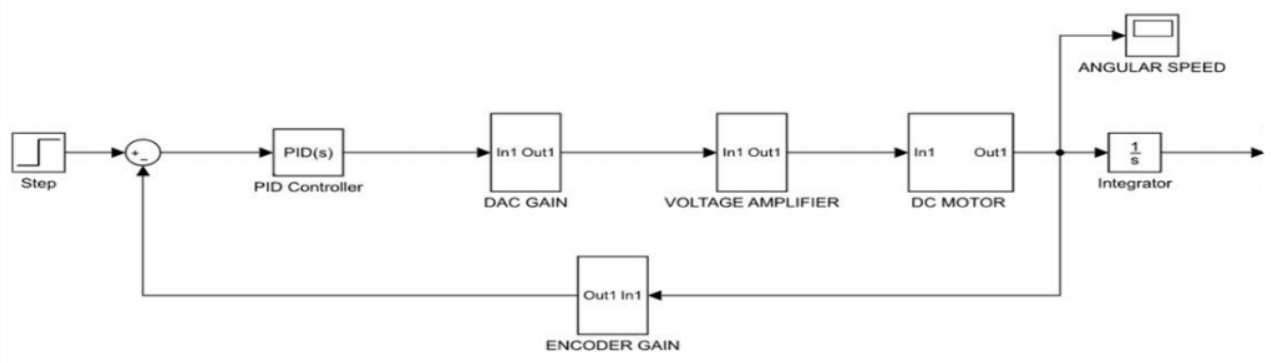

Figure 5 Simulink of construction for DC servomotor

Figure 6 shows the transfer function Simulink construction with closed-loop function. The motor wire winding tail has connected with the commutator for proper functioning in our proposed model. This proper arrangement of commutator setup is relying upon several paths.

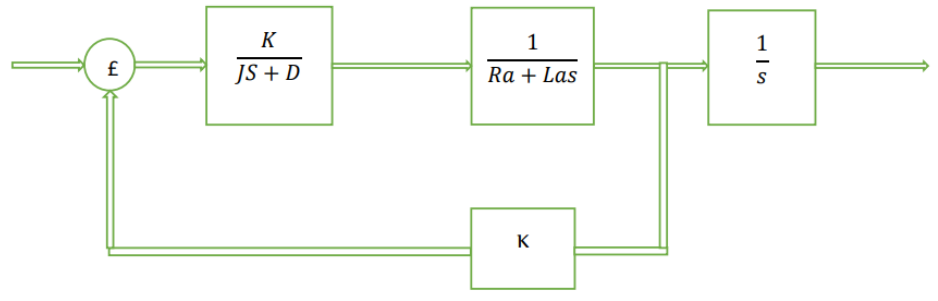

Figure 6 Simulation setup of Transfer function of DC motor

The graph depicts a smoother response settlement for the DC motor based on the derivation of a mathematical model of our fine-tuning PID controller. This achievement can direct the application to a smoother response to the smart wheelchair. This techniques is timeconsuming and provides quick responses. 
Journal of Electronics and Informatics (2021)

Vol.03/ No.01

Pages: 49-60

https://www.irojournals.com/iroei/

DOI: https://doi.org/10.36548/jei.2021.1.005

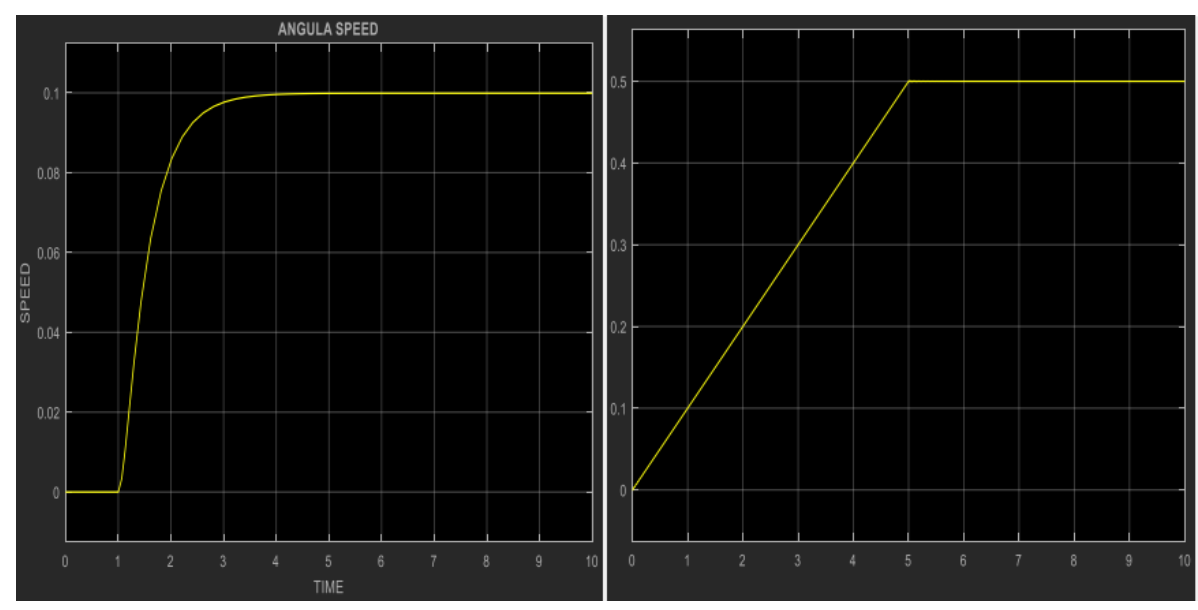

Figure 7 Simulink representation of DC servomotor

The stationary set of magnets present in DC motor construction enables the winding of the stator and rotor in the magnetic field. Generally, the windings are having multiple turns and are used to form a stationary magnetic field around [28] [29].

\section{CONCLUSION AND FUTURE SCOPE}

In the proposed mathematical model of DC servomotor supported EWC problems in a dynamic perspective. The Simulink output produces a smoother response in the angular speed with the time and early sensitive acceleration in the angle with a timely response. The derivative controller includes perfect angular movement tuning. It blends the optimization techniques with the angular speed response of a DC servomotor. This closed-loop performance for the application of EWC is a phenomenal approach. When analyzing the sensitiveness of the models, the proposed model is better than the existing model. Due to our fine-tuning with the derivative controller in our model, an immediate response during independent mobility of the EWC is provided. The model's execution time is significantly shorter than that of the existing model, making it suitable for image processing-based EWC (variable complex task). In the future, this proposed algorithm is applied practically in EWC with an image processing algorithm. At rapid phases, the proposed system is less resistant to variable load. Furthermore, the proposed system has a limited number of sensors. The proposed work's limitations will be taken into consideration. 
Journal of Electronics and Informatics (2021)

Vol.03/ No.01

Pages: 49-60

https://www.irojournals.com/iroei/

DOI: https://doi.org/10.36548/jei.2021.1.005

\section{REFERENCES}

[1] S.J. Suryawanshi and K. Janardhan Reddy, "Conceptual Product Development of Wheelchair for People Disabled in Legs", International Journal of Research in Mechanical Engineering, Vol.1, Issue 2, pp.01-10, October December, 2013.

[2] T.J. Alexander B. Martin, J.S.T. Rao and A. Ali, "Development of a Transformable Electrically Powered Wheel Chair into a Medical Emergency Stretcher", International Journal of Pharmacy and Technology, Vol.8, Issue No.2, June 2016

[3] J.J. John, J. Johnson, J.C. Joy , G. John and A. Johnson., "Multipurpose Medical Bed", International Journal of Engineering Research in Mechanical and Civil Engineering, Vol.1, Issue 5, September 2016.

[4] P. Norek, M. Ahmed, et al, "Livelihood Challenges for Extremely Poor Disabled People in the Southwest Costal Region of Bangladesh”, Shiree working paper 12, January 2013.

[5] R. C. Simpson, "Smart wheelchairs: A literature review", Journal of Rehabilitation Research \& Development (JRRD), Vol 42, Number 4, pp. 423-436, July/August 2005.

[6] M.E. Lund et al., "Inductive tongue control of powered wheelchairs", Proceedings of Annual International Conference of the IEEE Engineering in Medicine and Biology Society (EMBC), Buenos Aires, Argentina, pp. 3361 - 3364, 2010.

[7] I. Mougharbel, R. El-Hajj, H. Ghamlouch and E. Monacelli, "Comparative study on different adaptation approaches concerning a sip and puff controller for a powered wheelchair", Proceedings of IEEE Science and Information Conference (SAI), London, pp. 597 - 603, 2013.

[8] M. H. Alsibai, H. Manap and A. A. Abdullah, "Enhanced face recognition method performance on android vs windows platform", Proceedings of International Conference on Electrical, Control and Computer Engineering, Malaysia, 6 pages, 2015.

[9] M. K. Pathak, J. Khan, A. Koul, R. Kalane and R. Varshney, "Robot Control Design Using Android Smartphone," Journal of business management and economics, Vol. 3 (2), pp. 31 -33, February 2015.

[10] P. Mitzlaff, R. Niznik, R. Alqasemi and R. Dubey, "Universal Android-Based Kit for Wireless Control of Wheelchairs", Proceedings of ASME International Mechanical Engineering Congress and Exposition, Montreal, Quebec, Canada, pp. V003T03A059; 7 pages, 2014. 
Journal of Electronics and Informatics (2021)

Vol.03/ No.01

Pages: 49-60

https://www.irojournals.com/iroei/

DOI: https://doi.org/10.36548/jei.2021.1.005

[11] A. Milenkovic, M. Milosevic and E. Jovanov, "Smartphones for smart wheelchairs", Proceedings of IEEE International Conference on Body Sensor Networks (BSN), Cambridge, MA, USA, pp. $1-6,2013$.

[12] Q. Mourcou, A. Fleury, P. Dupuy, B. Diot, C. Franco and N. Vuillerme, "Wegoto: A Smartphone-based approach to assess and improve accessibility for wheelchair users", Proceedings of 35th Annual International Conference of the IEEE Engineering in Medicine and Biology Society (EMBC), Osaka, Japan, pp. 1194 - 1197, 2013.

[13] P. Sankhe, S. Kuriakose and U. Lahiri, "A Step towards a Robotic System With Smartphone Working As Its Brain : An Assistive Technology", Proceedings of IEEE International Conference on Control, Automation, Robotics and Embedded Systems (CARE), Jabalpur, India, pp. 1 - 6, 2013.

[14] J. Kim, H. Park and M. Ghovanloo, "Tongue-Operated Assistive Technology with Access to Common Smartphone Applications via Bluetooth Link", Proceedings of 34th Annual International Conference of the IEEE EMBS, San Diego, California USA, pp. 4054 - 4057, September, 2012.

[15] A. Danquah-Amoah et al., "Assistive Robotic Wheelchair Using Voice And Bluetooth Control", International Journal of Scientific Research Engineering \& Technology (IJSRET), Volume 2, Issue 9, pp. 553 - 559, December 2013.

[16] A. V. Nguyen, L.B. Nguyen, S. Su and H. T. Nguyen "Shared control strategies for human Machine interface in an intelligent wheelchair", Proceedings of 35th Annual International Conference of the IEEE Engineering in Medicine and Biology Society (EMBC), Osaka, Japan, pp. $3638-3641,2013$

[17] H. Uchiyama et al., "A Semi-Autonomous Wheelchair with HelpStar", Innovations in Applied Artificial Intelligence. Springer Berlin Heidelberg, pp. 809 - 818, 2005.

[18] C. Gao, M. Sands and J. R. Spletzer, "Towards Autonomous Wheelchair Systems in Urban Environments", Field and Service Robotics Results of the 7thInternational Conference, Vol. 62, Springer Berlin Heidelberg, 2010.

[19] A. Antonis et al., "Semi-autonomous navigation of a robotic wheelchair", Journal of Intelligent and Robotic Systems Vol 34(3), pp. 315-329, 2002. 
Journal of Electronics and Informatics (2021)

Vol.03/ No.01

Pages: 49-60

https://www.irojournals.com/iroei/

DOI: https://doi.org/10.36548/jei.2021.1.005

[20] O. Postolache, P. S. Girão, G. Postolache and J. Gabriel, "Cardio-Respiratory and Daily Activity Monitor Based on FMCW Doppler Radar Embedded in a Wheelchair", Proceedings 33rd Annual International Conference of the IEEE Engineering in Medicine and Biology Society EMBS, USA, pp. 1917 - 1920, 2011

[21] C.J. Liang, S. C. Kang, Y.Y. Yang, P. C. Lin, Y. S. Lin and Y.C. Chen, "BotBeep - An Affordable Warning Device for Wheelchair Rearward Safety", Proceedings of IEEE International Conference on Orange Technologies (ICOT), Taiwan, pp. 159 - 163, 2013

[22] R. J. Linton, J. Schaufeld and T. Padır, "Smart Wheelchairs or Not: Lessons Learned from Discovery Interviews", Proceedings of IROS Workshop on Rehabilitation and Assistive Robotics: Bridging the Gap between Clinicians and Roboticists, USA, 2014.

[23] Lin, P.H. Hwang, S. and Chou, J., Comparison on Fuzzy Logic and PID Controls for a DC Motor Position Controller. Conference Record of the 1994 IEEE Industry Applications Society Annual Meeting, 1930-1935, (1994).

[24] Mishra, M.K., Kothari, A.G., Kothari, D.P. and Ghosh, A., Development of a Fuzzy Logic Controller for Servo Systems. IEEE Region 10 International Conference on Global Connectivity in Energy, Computer, Communication and Control (TENCON '98), 204-207, (1998).

[25] Kwon C. J., Han W. Y., Kim S. J. and Lee C. G., "Speed Controller with Adaptive Fuzzy Tuning for BLDC Motor Drive under Load Variations", SICE Annual Conference in Fukui, 2003, pp. 2696-2699.

[26] Zadeh, M. H., Yazdian, A. and Mohamadian, M., Robust Position Control in DC Motor by Fuzzy Sliding Mode Control. International Symposium on Power Electronics, Electrical Drives, Automation and Motion (SPEEDAM 2006), 1413-1418, 2006.

[27] James J. Kauzlarich., "Wheelchair caster shimmy II: Damping”, Journal of Rehabilitation Research and Development, Volume. 37, No. 3, pp. 305- 313, May/June 2000.

[28] V. Santhanam and V. Viswanathan, "Smartphone accelerometer controlled automated wheelchair", Proceedings of the 3rd International Conference on Electronics, Biomedical Engineering and its Applications, Hong Kong, China, pp. 57 - 61, 2013.

[29] Manafeddin Namzov \& Onur Basturk.DC motor position control using fuzzy proportionalderivative controllers with different defuzzification method. An official journal of Turkish Fuzzy System association (Vol.1 No.1,pp. 36- 54,2010). 